\title{
El valle de Lecrín en el Atlas del Patrimonio Inmaterial de Andalucía
}

Inmaculada Álvarez Bejarano | Centro de Documentación y Estudios, Instituto Andaluz del Patrimonio Histórico

URL de la contribución <www.iaph.es/revistaph/index.php/revistaph/article/view/3915>

\section{RESUMEN}

El valle de Lecrín es una comarca enclavada en la vertiente meridional de Sierra Nevada, al sur de la provincia de Granada. Su privilegiada situación, su acusada personalidad, su importante red hídrica y sus especiales condiciones climáticas, entre otros factores, van a ser determinantes en su historia y modos de vida. Respecto a las manifestaciones de su patrimonio inmaterial hay que resaltar su vinculación a unos procesos históricos, económicos y sociales comunes al territorio y de significados colectivos.

En cuanto a los rituales festivos destacar que la mayoría de ellos se concentran en los meses de enero, mayo, agosto y septiembre, coincidiendo con el calendario agrícola. Los oficios y saberes van a estar ligados a las principales actividades económicas del valle: agricultura, sobre todo a los cultivos de regadíos que se complementan con los de secano (cítricosolivar), y ganadería. La tradición culinaria la podemos encontrar asociada tanto a determinados contextos festivos como formando parte de la dieta cotidiana de la localidad.

\section{Palabras clave}

Alimentación | Andalucía | Modos de expresión | Oficios | Patrimonio inmaterial | Rituales festivos | Valle de Lecrín | 


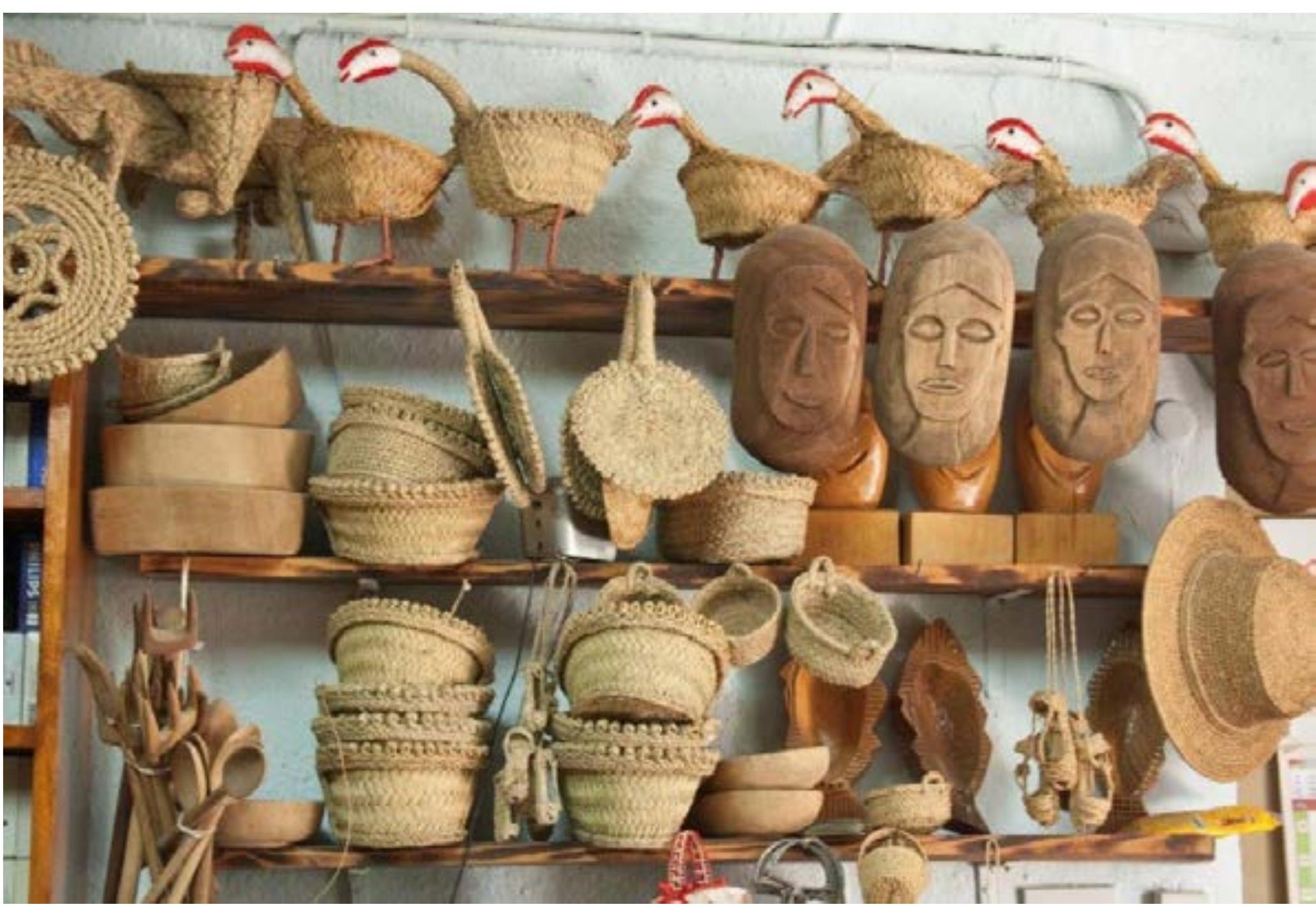

Objetos de espartos. Albuñuelas | foto Maria del Rosario Ortiz Amores, de todas las imágenes del artículo 
1

Para la redacción del Atlas del Patrimonio Inmaterial de Andalucía, en la Fase 2, Zona 5, M. ${ }^{a}$ del Rosario Ortiz Amores se encargó de la recopilación de información y elaboración de documentación técnica sobre el valle de Lecrín. Su trabajo ha sido consultado para la elaboración de este artículo.
El valle de Lecrín es una pequeña comarca enclavada en la vertiente meridional de Sierra Nevada, al sur de la provincia de Granada. Su situación privilegiada, a medio camino entre la vega del Genil, la costa, la Alpujarra y el Temple, hacen de este valle un estratégico pasillo natural que va a marcar su historia y modos de vida.

Se trata de un territorio de acusada personalidad que participa de las características de las comarcas circundantes, pero que a su vez goza de unas especiales condiciones climáticas, constituyendo una magnífica solana que, resguardada de los vientos fríos del norte por la propia sierra, ha permitido crear una agricultura intensiva en terrazas, completamente diferente a la del resto de la provincia.

Territorialmente se diferencian los municipios de El Padul y Dúrcal, más próximos a la capital, Granada, que por su número de habitantes y actividades económicas se pueden considerar que han alcanzado el nivel de agrociudades. Mientras que los pequeños municipios y las localidades que los componen, como Albuñuelas, Villamena, Lecrín, El Valle o El Pinar, incluyendo Nigüelas, constituyen una unidad económica y cultural.

En el Atlas del Patrimonio Inmaterial de Andalucía ${ }^{1}$ se han documentado alrededor de 25 elementos correspondientes al valle de Lecrín distribuidos entre los siguientes ámbitos temáticos: rituales festivos, oficios y saberes, modos de expresión y alimentación y cocinas, teniendo en consideración los procesos históricos, económicos y sociales comunes al territorio de esta comarca.

\section{RITUALES FESTIVOS}

En el valle de Lecrín el mayor número de manifestaciones festivas se concentran en los meses enero, mayo, agosto y septiembre, relacionadas principalmente con las actividades agrícolas productivas. El calendario festivo anual se inicia el 6 de enero con la fiesta del mosto en Cónchar, en torno a la producción vinícola de esta localidad. La organización corre a cargo de la Hermandad de Ánimas que, de igual modo, se hace responsable de la "rifa de ánimas", que se lleva a cabo cada uno de enero en la plaza de San Pedro. Durante la misma diversos productos, que en décadas anteriores procedían de la producción agrícola propia, se subastan al mejor postor.

Béznar celebra el diecisiete de enero la fiesta de San Antón. San Sebastián se celebra en Padul el diecinueve y veinte de enero y Dúrcal celebra cada dos y tres de febrero el día de San Blas. Patrones cada uno de ellos de sus respectivas localidades, a los que la tradición y leyendas atribuyen la protección de cosechas, sequías, epidemias, fenómenos relacionados con la natu- 

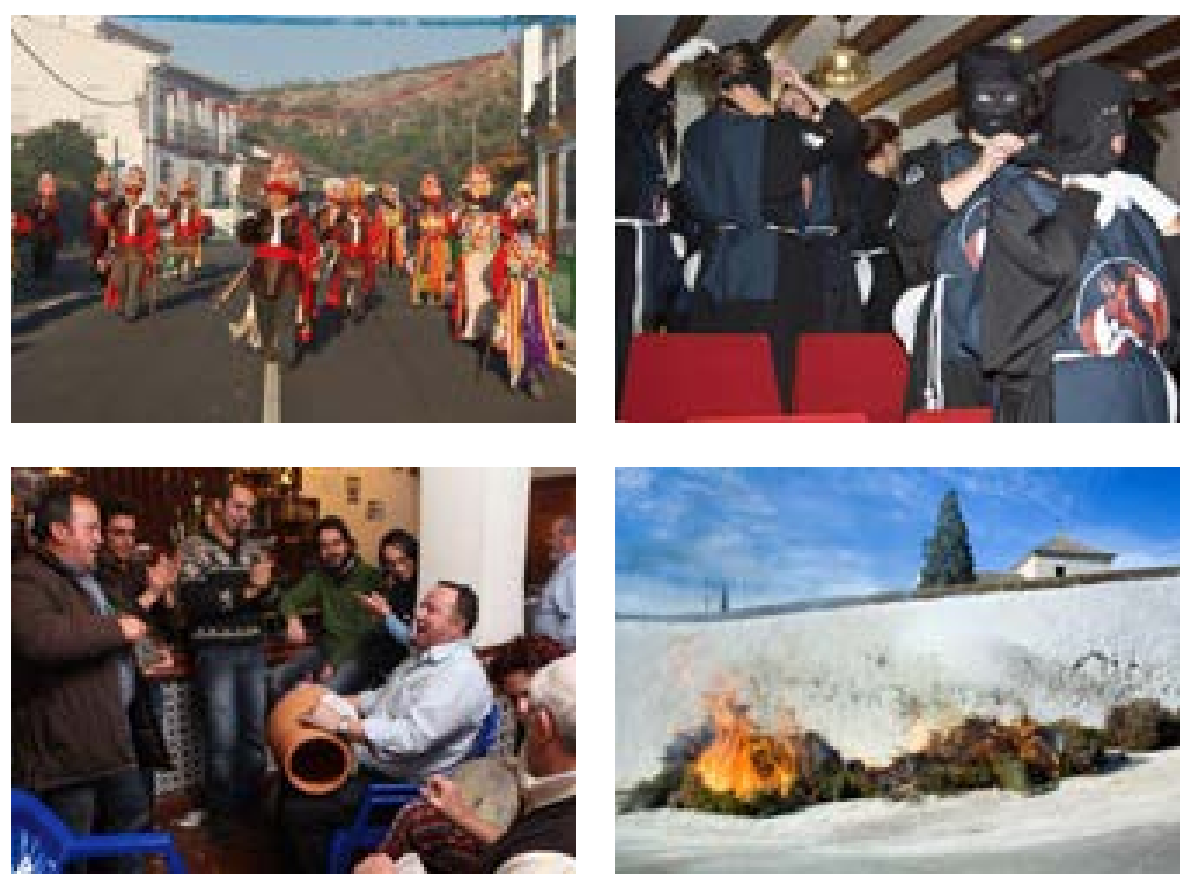

Mosqueteros. Béznar (imagen superior izquierda)

Miembros del a cofradía de la Zorra. Nigüelas (superior derecha)

Fiesta del mosto. Villamena (imagen inferior izquierda)

Hogueras de San Sebastián. Padul (inferior derecha)

raleza y también con algunas enfermedades. Es común en estos rituales la utilización del fuego como elemento purificador, ya sea como hogueras, que en algunos casos alumbrarán el itinerario de la procesión del patrón, o también en forma de cohetes, bengalas y ruedas de fuego.

Transcurridos sesenta días del Domingo de Resurrección se celebra la festividad del Corpus, que tradicionalmente en Albuñuelas se llevaba a cabo el jueves. Los preparativos ocupan fundamentalmente a los vecinos que días antes encalan sus fachadas, orean las colchas bordadas, que penderán de sus balcones, y se desplazan al campo para recolectar el tomillo, romero "pinico", "gallombas" y mastranzo con el que se alfombrarán las calles del itinerario procesional.

De igual modo, durante la noche de la víspera grupos de vecinos se reúnen para montar los altares, que lucirán el día de la procesión de la custodia, y se suelen consumir buñuelos con chocolate para atenuar el cansancio.

La localidad de Cozvíjar celebra el primer fin de semana de agosto las fiestas de su patrona, la Virgen de la Cabeza. La noche del domingo, entre la humareda de una atronadora tirada de cohetes, sale en procesión la imagen de la Virgen de la Cabeza, acompañada por gran número de devotos, muchos procedentes de municipios cercanos como Padul y Cónchar. Durante el recorrido son numerosas las ofrendas florales y la quema de ruedas de fuegos artificiales en agradecimiento a la Virgen. 


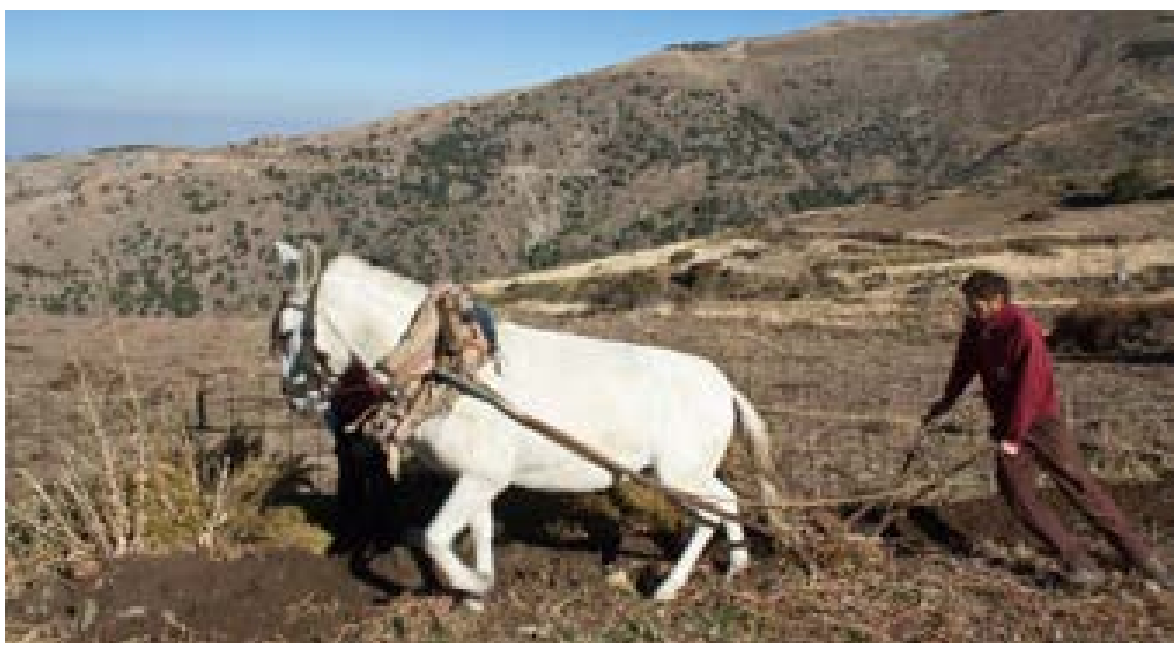

Cosechado de patatas con arado. Nigüelas

Pinos del Valle celebra las fiestas en honor a su patrón, san Roque, con motivo de su onomástica, el dieciséis de agosto. Los actos dan comienzo la jornada del quince, día de la Asunción, con una diana musical, una función religiosa a mediodía y, sobre las nueve de la noche, la salida en procesión de la Virgen acompañada por san Roque, que parte de la iglesia del barrio bajo con destino a la iglesia de San Sebastián en pleno barrio alto para "llevarse invitado a san Sebastián a dormir en casa de ellos, abajo". Una vez allí se incorpora al cortejo la imagen de san Sebastián para iniciar el recorrido que los conducirá de nuevo al barrio bajo, donde permanecerán hasta la jornada siguiente.

El ritual festivo conocido como los Mosqueteros del Santísimo Sacramento se celebra en el municipio granadino de Béznar durante el primer fin de semana de septiembre en honor al patrón de la localidad, san Antón. Se trata de una celebración en la que se recuerda la victoria de un grupo de vecinos, convertidos en milicia, sobre los moriscos durante el reinado de Felipe II, lo que se ha venido en llamar la "rebelión de las Alpujarras". Los mosqueteros, grupo conformado por un cabo, un teniente alférez, un sargento abanderado y una veintena de mosqueteros, protagonizan la mayoría de los actos que se desarrollan durante las jornadas del sábado y el domingo.

La ceremonia del entierro de la zorra comienzan unos veinte días antes de las fiestas patronales de Nigüelas en honor de la Virgen de las Angustias, el tercer fin de semana de septiembre. Se piensa que en origen era un acto de expiación de los males y desgracias sufridos durante el año.

La localidad granadina de Talará, en pleno valle de Lecrín celebra en la primera quincena del mes de diciembre la Fiesta de la Inmaculada Concepción, coincidiendo con la jornada del ocho, día de la Purísima. Con tres meses de 


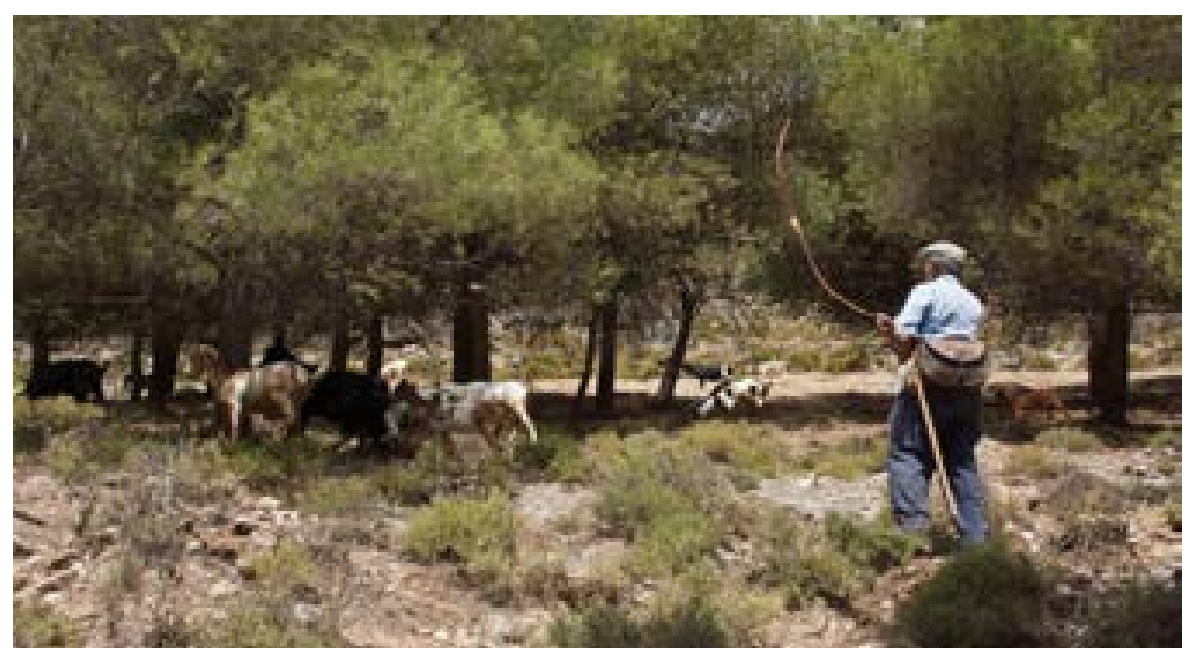

Pastor con onda. Albuñuelas

antelación comienzan los preparativos. Una comisión vecinal creada a tal efecto se encarga de organizar y recaudar los fondos necesarios para financiar la festividad que cada año es asignada a una calle de la localidad.

\section{OFICIOS Y SABERES}

Tradicionalmente, la vida en el valle ha estado ligada a actividades agrícolas, sobre todo a los cultivos de regadío, que se complementan con los de secano y con actividades ganaderas (pequeños rebaños de cabras y ovejas, ganado vacuno estabulado o semiestabulado) y forestales. Este panorama, poco a poco se está diversificando, cobrando fuerza actividades no rurales ligadas a los sectores secundario y terciario.

La creación de un paisaje agrario en una zona con una red hídrica tan importante conllevó un dominio de las técnicas de abastecimiento de agua. A lo largo de las vegas pueden verse numerosas construcciones relacionadas con la captación, distribución y almacenamiento de agua: pozos, acueductos, acequias, aljibes, fuentes, etc. Estrechamente vinculada a toda esta infraestructura, nos encontramos con una importante producción de cítricos y árboles frutales, entre los que destaca la naranja.

En todo el valle de Lecrín en general, el olivar representa una actividad económica que alcanza una producción importante, aunque en su mayor parte no es de secano, sino que también ocupa zonas de regadío. En algunos municipios de la localidad de El Valle, los olivos se encuentran en las fincas junto con los naranjos, ocupando los linderos de estas, de tal forma que, por su gran envergadura, protegen a los cítricos y, al mismo tiempo, se benefician de los cuidados que éstos reciben. Hoy día, existe una centrali- 


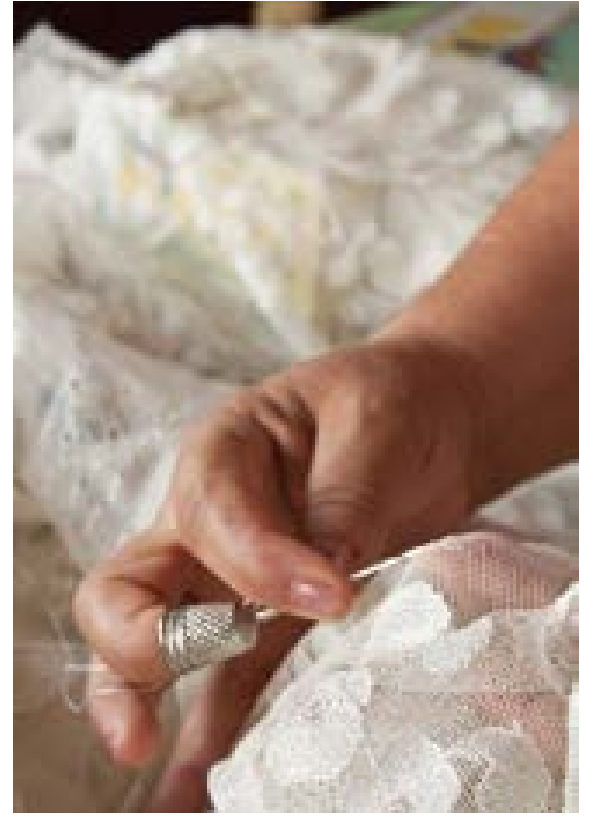

Bordado en tul. El Pinar zación de la producción de aceite en las localidades como Pinos o Nigüelas, habiendo desaparecido la mayoría de los molinos en el resto de municipios de la comarca.

La producción de patatas de la sierra, es una actividad económica tradicional en la localidad de Nigüelas. Durante muchos años fue la producción principal de invierno de la vega y tenían gran fama pues servían de simiente o semilla para las vegas del valle, Granada y la costa. El cultivo y recolección de la patata que ha servido para alimentar a varias generaciones y en ocasiones ha estado destinado al trueque o intercambio por otros productos, conserva las técnicas tradicionales para la siembra y recolección; realizándose con el arado de vertedera con tiro de mula.

Respecto a la actividad vinícola, la vid nunca ha constituido un cultivo fundamental, sin embargo todos los municipios destinaban pequeñas extensiones al viñedo y, en algunos de ellos, llegó a alcanzar cierta importancia, como en Nigüelas y Dúrcal, destacando Pinos del Valle, Cónchar y Albuñuelas (tierras de viñas), donde en la actualidad existe una importante producción de vino. El "vino de la tierra" se destina principalmente al autoconsumo, aunque puede ser utilizado como intercambio entre vecinos de otros productos de la zona, como aceite o patatas.

La espartería es uno de los oficios tradicionales vinculado al medio que refleja, la importancia que alcanzó la transformación de la fibra natural en tejidos útiles y aparejos de labranza en muchos de los municipios del valle del Lecrín, destacando la tradición del esparto en municipios como Padul y Dúrcal. En este último municipio se llegó a dar la mayor especialización realizándose en sus fábricas una labor que generó gran número de mano de obra hasta bien entrado el siglo XX: la elaboración de tomiza mediante rueca.

La enea, también llamada nea o anea, es una planta alta de hojas largas que nace silvestre en los márgenes de los ríos dentro del agua. Se recoge entre los meses de junio a agosto. Eran las mujeres las que se encargaban de, como se conoce popularmente,"cogerle el culo a la silla", oficio que habían aprendido de sus padres o abuelos. Las sillas de enea formaban parte del mobiliario de la mayoría de las casas y de las iglesias de la localidad. Cuando se estropeaban se llevaban a los domicilios particulares de las mujeres, que después de terminar las tareas del campo o entre las domésticas, "mientras hervía la comida, se echaba el culo", se encargaban de estos trabajos cuyos ingresos contribuían a la débil economía familiar.

También la tradición ganadera se ha mantenido como una constate a través del tiempo en la mayoría de las poblaciones que componen la comarca del valle siendo el pastoreo una actividad importante en localidades como 


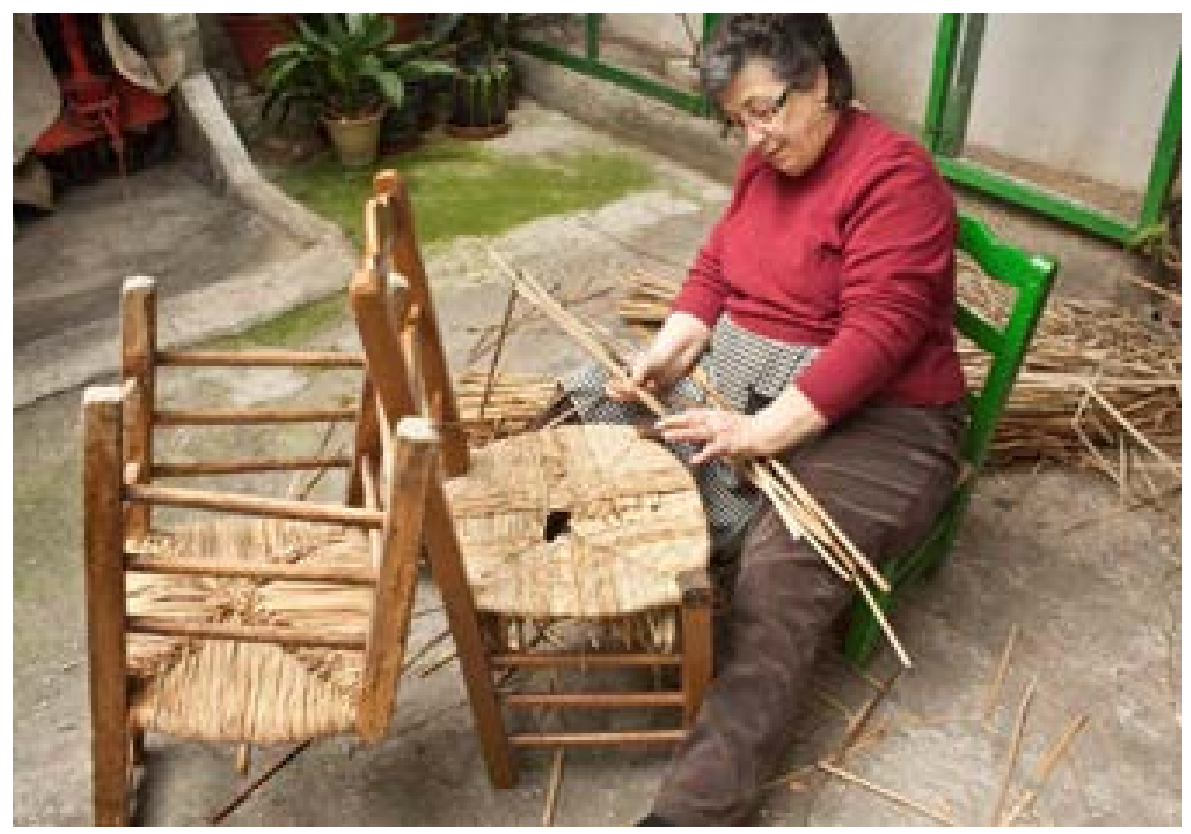

Sillas de enea. Nigüelas

Albuñuelas que, junto con Nigüelas y Padul, componen los municipios situados a mayor altura en el valle. Oficio éste que se ha trasmitido de padres a hijos y ha permitido vivir a los pequeños propietarios de los rebaños aunque con grandes dificultades.

La carpintería artesanal destinada a la elaboración de los aparejos de los animales de tiro, équidos (caballos, burros y asnos) y los bóvidos como los bueyes es otro de los oficios de cierta importancia en la comarca. Además, se elaboran también con procedimientos artesanales los utensilios de madera necesarios para las tareas del campo, astiles y trilla.

El bordado en tul de seda, cuyo origen se puede remontar más allá de la época musulmana, se ha desarrollado y conservado a lo largo de los tiempos en muchos de los pueblos del valle de Lecrín y, en particular, en Pinos del Valle. Trabajos de bordados que formaban parte de las labores que las mujeres realizaban en sus domicilios. Estas mujeres bordadoras supieron rentabilizar estos conocimientos comercializando sus trabajos a cambio de ciertas cantidades de dinero que empleaba en compras extraordinarias para la unidad familiar.

\section{MODOS DE EXPRESIÓN}

En Dúrcal durante las fiestas y en los momentos invernales se jugaba al "Paulo". Se piensa que desde el siglo XVIII ha estado siempre vinculado a la 


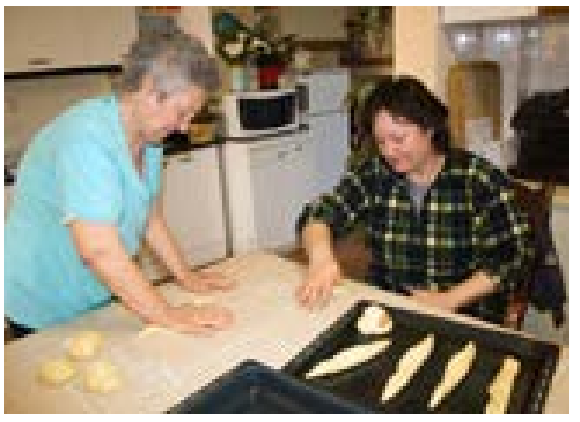

Elaborando hornazos. Dúrcal

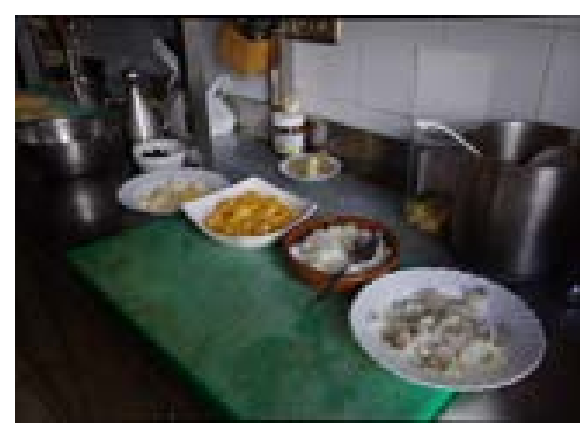

Ingredientes del remojón. Villamena

agricultura. Sobre todo durante la época de lluvia que paraban las tareas del campo, el Paulo, se convertía en una forma que los hombres tenían de pasar el tiempo con los amigos. Es un juego donde no hay dinero de por medio pues el fin principal no es lucrativo sino de entretenimiento.

En la festividad de la Virgen del Rosario, patrona de un gran número de municipios del valle, se canta el rosario de la aurora por las calles de la localidad. En localidades como Melegís, la salve a la Virgen del Rosario ha supuesto con el tiempo un modo de expresión que se ha convertido en símbolo de la identidad local.

\section{ALIMENTACIÓN Y COCINAS}

Respecto a la tradición culinaria de la comarca, encontramos platos asociados por un lado a contextos festivos como Semana Santa, Navidad, etc. y también los vinculados a las celebraciones en honor a determinados santos. De otro lado, nos encontramos con platos cuyo consumo forma parte de la dieta cotidiana.

Es común en los municipios que componen la comarca del valle de Lecrín, entre otros Albuñuelas, Pinos del Valle, Melegís, Restábal, Saleres, Acequias, Béznar, Chite, Mondújar, Talará, Nigüelas y Padul, la elaboración de un plato conocido como remojón. Se trata de una ensalada que se solía preparar en invierno y cuya peculiaridad son sus ingredientes a base de naranja, cebolla, aceitunas, bacalao asado y orejones de tomates secos.

El hornazo es un panecillo de aceite, cuya forma más común es de torta redonda, con dos especies de brazos cruzados, que cubren un huevo duro que contiene en su interior. En Dúrcal se consume durante Domingo de Resurrección y Lunes de Pascua para celebrar la fiesta del Hornazo. En los día previos a las fiestas, madres e hijas se reúnen para elaborar los hornazos en las casas a partir de una receta que con el tiempo ha experimentado pocos cambios. En Dúrcal, es costumbre romper los huevos de los hornazos 


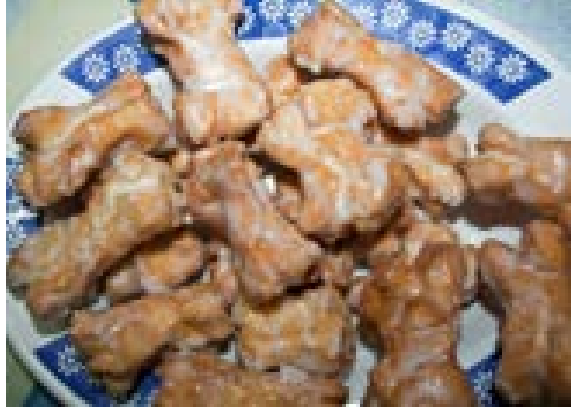

Palillos. El Pinar

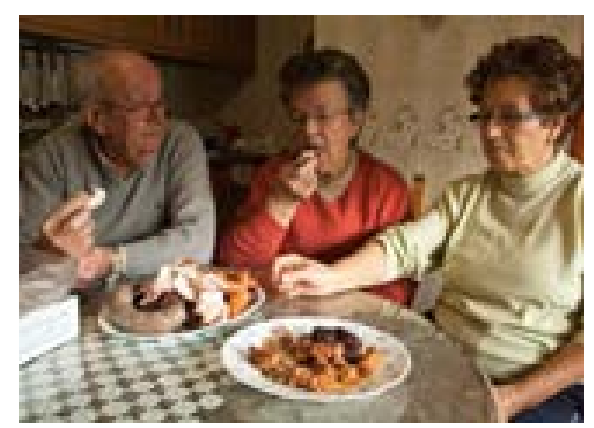

Comiendo garlopa. Lecrín

en las cabezas de las personas que estén más a mano, en señal de buena suerte.

La olla de San Antón, conocida popularmente en Béznar como el testú, se elabora cada año después de las matanzas con productos del cerdo e ingredientes que suavizan la grasa. Era y es un plato familiar que se consume en invierno por el alto grado de ingestas calóricas y que en el día del patrón de Béznar, san Antón, se convierte en la comida previa a la procesión del santo.

La garlopa es un plato que se elabora en Chite con productos de la matanza. Las mujeres eran las que solían prepararla desde antaño para la Rifa de los Inocentes.

En la localidad de Pinos, además de en la celebración de sus fiestas patronales, cada año se elaboran, en el mes de noviembre, como en otros municipios de la comarca del valle de Lecrín, los dulces conocidos por huesos de santos. Una vecina de la localidad, con la base de estos dulces de santos, introdujo un modo nuevo de elaboración artesanal, y difundió sus enseñanzas de forma oral entre las mujeres de Pinos, dando lugar a los dulces que se conocen como palillos que pasaron a formar parte de los dulces que cada año preparan las amas de casas con motivo de la celebración de la Navidad. 